\title{
Knowledge Creation at FORTUM Engineering
}

\author{
P. Valikangas, J. Puttonen, M. Sulkusalmi \\ Fortum Engineering Ltd, Finland \\ Em: pekka.valikangas@fortum.com
}

\author{
A.S. Kazi, M. Hannus \\ VTT Building Technology, Finland \\ Em:Sami.Kazi@vtt.fi
}

Keywords Knowledge Mining and Creation, Information Infrastructure, Virtual Enterprise, Fortum Engineering

\begin{abstract}
The creation and management of knowledge is considered a key enabler of value added business process delivery. This paper presents the findings of the main efforts towards knowledge creation at Fortum Engineering (FE), an engineering, procurement, and construction provider of power plants. Dealing with different levels of knowledge, it is necessary for FE to provide an environment that is able to translate and codify its tacit knowledge into explicit knowledge to support the definition of power plant configurations using expert applications. Where data or information is not available in a tangible form for translation, some mapping methodologies may be used to render the tacit knowledge meaningful and usable. FE's suggested, knowledge creation and management environment involves; mining of data structures to capture and transfer information into the appropriate knowledge level, manual and automated inputs and rule definitions to capture and manage knowledge on different knowledge levels, and the correlation of knowledge and its data or information source using mind mapping tools. The focus of this paper is to first justify the need for knowledge creation at $\mathrm{FE}$ and then to illustrate the envisioned knowledge creation environment. Key phases of the knowledge creation process are furthermore explained.
\end{abstract}

\section{INTRODUCTION}

Knowledge is an organisational capital that needs to be exploited to its full potential for value added business process delivery. The aim being to both increase and enable an individual to participate in decision-making 
based on value-added information in addition to being in a position to exercise control over person's work domain.

One of the key success factors for an engineering company is the ability to share and, where possible, formalise its tacit knowledge into a meaningful form. This is then to be used by both its knowledge workers and seekers alike, in addition to being stored and used within the company's own expert applications for power plant design. The core underlying purpose being to "first sieve the wheat from the chaff and then to sieve out the real drops of wisdom relevant for the topic under concern" [1].

\section{NEED FOR KNOWLEDGE CREATION AT FE}

Fortum Engineering (FE) is part of the Fortum Group, a diversified group of companies in the energy industry. Three Fortum companies are cooperating in the main business area of FE: FE, Fortum Power and Heat Ltd and Fortum Services Ltd. FE is selling power plants as a constructor by managing engineering, procurement and construction. Fortum Power and Heat is selling energy as the owner of power plants and is a client of power plant delivery. Fortum Service is an operator of power plants and selling more coverage to energy production and at the same time taking part in the bid from a total life cycle aspect.

Figure 1 below describes the total life cycle of a power plant from the viewpoint of information management in the Fortum Group. This is the forum, where the knowledge is supposed to be available especially for tender design purposes.

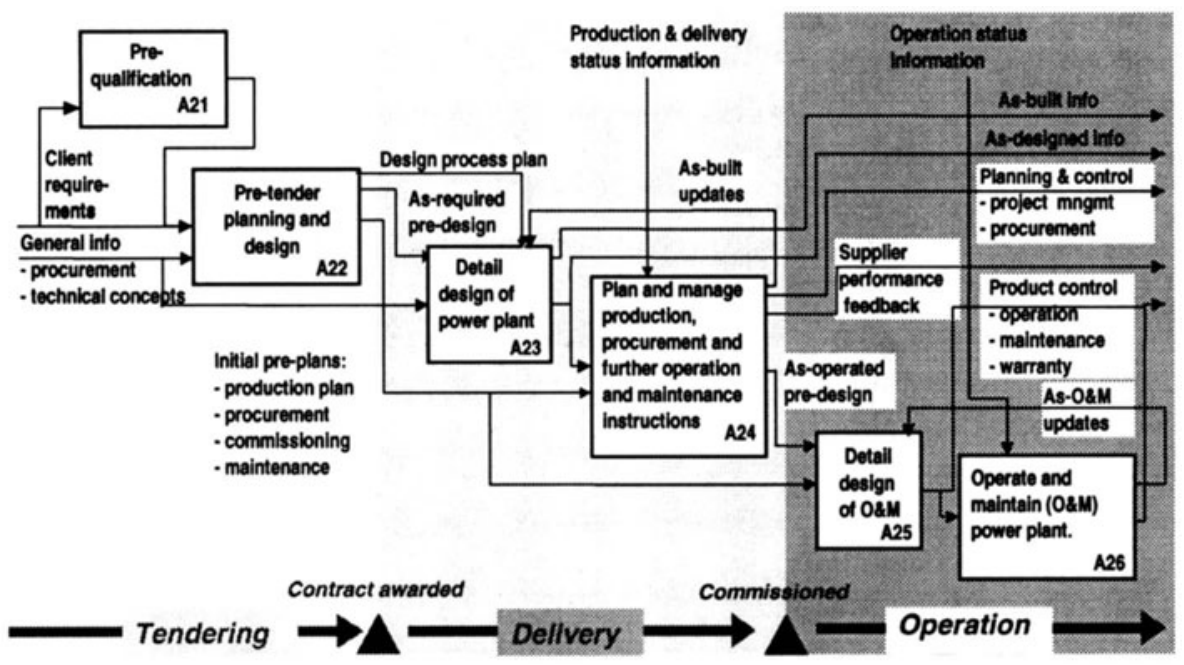


The need for efficient co-operation with affiliated companies and clients under high demands on total delivery of power plants and low margin of profit drive the company to develop constantly its engineering technology and associated applications. FE is developing and implementing an expert system for tender phase design in order to define suitable power plant products with cost estimates for different clients. The expert system is using formalised knowledge based product models and design rules.

The collection and development of formalised knowledge is both laborious and tedious among the collectors, developers of the expert system and sources of information, the technical experts in the company. It is also difficult for people from different technical backgrounds to understand each other. The need therefore is evident for a knowledge creation environment where the tacit knowledge of key persons could be formulated to be in the form of structured rules for the expert system. The known explicit knowledge (in addition to some remaining tacit knowledge) may be linked to the relevant product descriptions through the expert system, thereby providing pointers to key sources of information and knowledge.

The creation of knowledge is a joint venture within the Fortum Group. The road ahead is through the development and exploitation of knowledge technology.

\section{DEVELOPMENT OF KNOWLEDGE TECHNOLOGY}

The development of knowledge technology is seen as the next major challenge for engineering businesses. A brief look at recent history makes it possible to understand a common tendency towards the development of engineering science and design tools. Figure 2 shows three basic trends of uprising new kinds of applications for design.

The Finite Element Method and Computer Aided Design have already demonstrated the potential of new computer based technology in their straightforward development and implementation in engineering companies. This work has resulted in high levels of efficiency in engineering design and consequent implications to the performance of organisations. FE has been on the forefront in taking these technologies on board from the very beginning and has been successful in its endeavours. Consequently the willingness and determination to continue with such engineering development work is omnipresent.

Knowledge technology is the emergent trend towards bringing in new kinds of possibilities and tools to engineering business. This trend is probably even stronger and larger than the previous ones, because it is 
developing in accordance with the evolution of Internet technology. These trends have similar development features in the form of strong theoretical and educational development, clear growing market needs and substantial amount of developers and vendors.

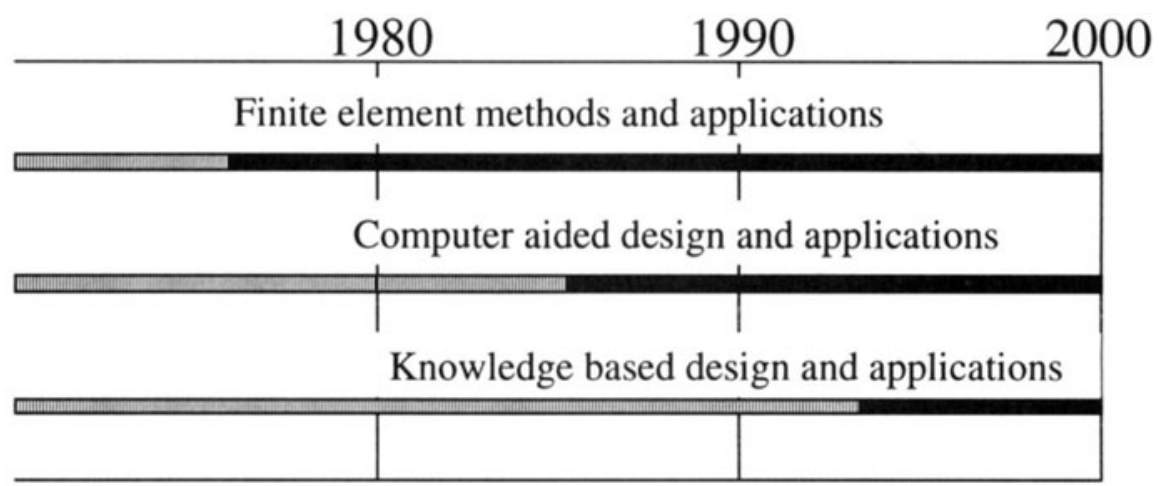

Figure 2 Trends of engineering science and design tools.

Good examples and encouragement have been found from the experiences of the Japanese industry as studied and presented by Nonaka and Takeuchi [2]. Davenport and Prusak [3] have provided valuable insights to knowledge management whereas von Krogh et al. [4] have done so for knowledge creation.

The problem of FE is that even if there seems to be a common vision of knowledge creation in accordance with knowledge based expert systems no suitable tools are available for quick implementation into FE's process. Therefore the focus is to develop methods and implement tools to get an effective environment for knowledge creation and management by which a better support can be offered during the tender phase of power plants.

\section{KNOWLEDGE CREATION ENVIRONMENT}

The development of a knowledge creation environment is a continuous development effort at FE. Figure 3 presents the role of the knowledge creation environment, where the existing product data, construction and operational experiences are used to enhance existing and create new value added company knowledge. This will further support tender phase application development so that the client's requirements can be taken into account more efficiently. 
It is suggested that knowledge evolution goes through a sequential process from tacit knowledge to rules in the expert system for the tender design of different kind of power plants. The goal is to get an environment, which also enables the creation of new knowledge - see Figure 4.

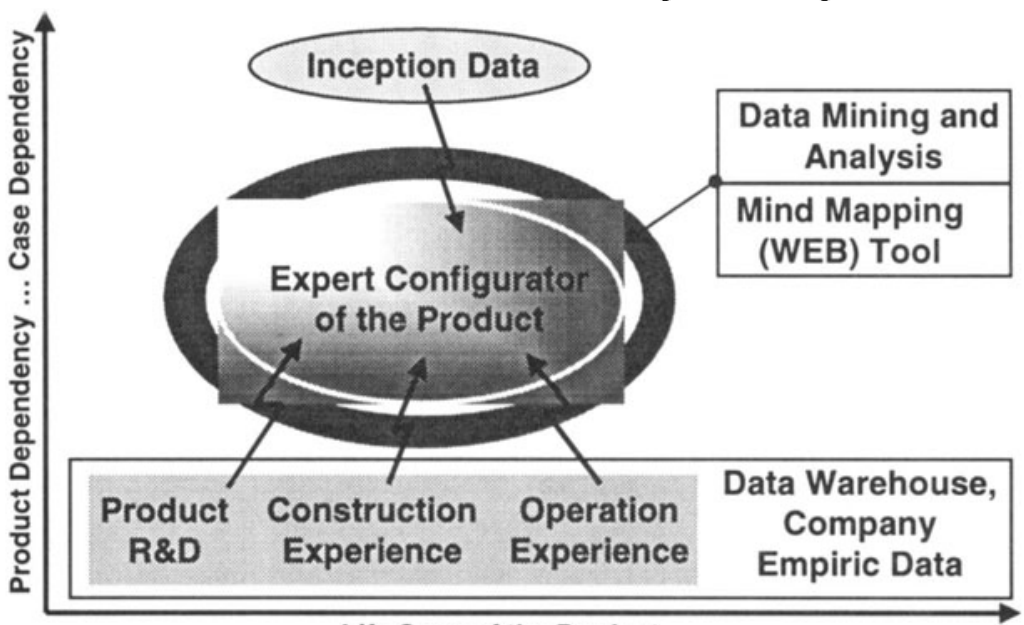

Life Span of the Product

Figure 3 Knowledge creation environment in Fortum Engineering.

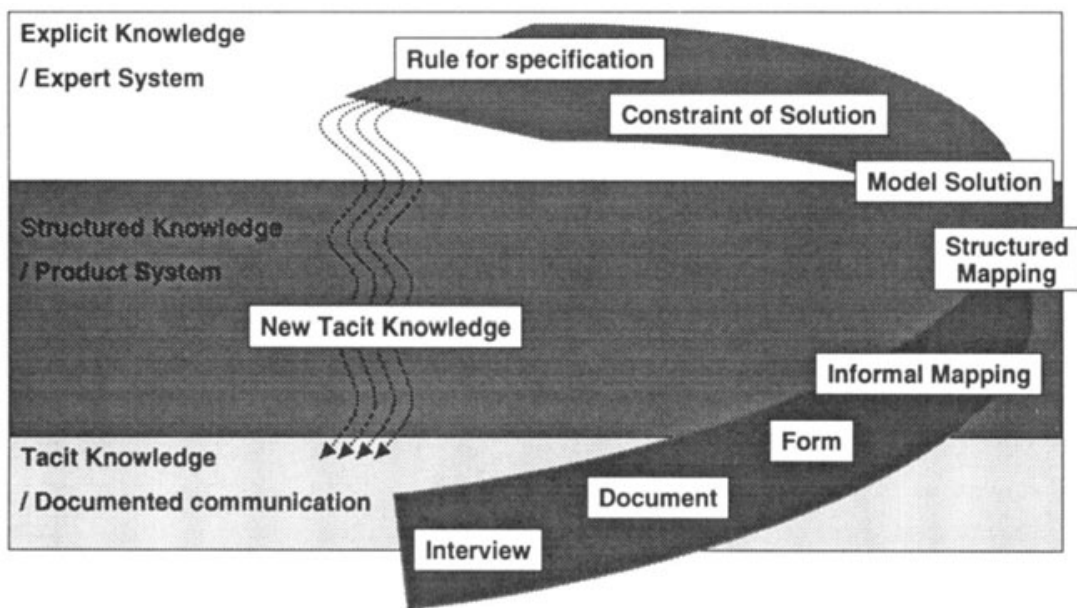

Figure 4 Evolution of knowledge

Table 1 lists the different forms of knowledge and describes their correspondent formats. Table 2 lists the users of the knowledge creation environment and describes their roles. 


\section{KEY PHASES IN KNOWLEDGE CREATION}

\subsection{Informal Mapping}

Mind mapping is a method for collecting and structuring information into informal knowledge. Figure 5 shows an example of how the design knowledge of equipment may be mapped.

Table 1 Evolution phases of knowledge.

\begin{tabular}{ll}
\hline Phase of knowledge & Format / Description \\
\hline Rule for specification & Code of Lisp and JAVA in expert systems for rule specification \\
\hline Constraint of solution & $\begin{array}{l}\text { Code of Lisp and JAVA and formulas of checkpoints in expert } \\
\text { systems }\end{array}$ \\
\hline Model solution & $\begin{array}{l}\text { CAD-files and Database connected to product model of expert } \\
\text { systems and also presented in design guides }\end{array}$ \\
\hline Structured mapping & $\begin{array}{l}\text { Unified Modelling Language (UML) for linking logical structures } \\
\text { of power plant techniques and product model of expert system }\end{array}$ \\
\hline Informal mapping & Mind mapping for logical structures of power plant techniques \\
\hline Form & GUI dialogues and database \\
\hline Document & $\begin{array}{l}\text { Textual, spread sheet and CAD files in document management } \\
\text { system }\end{array}$ \\
\hline Interview & $\begin{array}{l}\text { Discussions between experts of power plant techniques and } \\
\text { knowledge engineering }\end{array}$ \\
\hline New tacit knowledge & New data in databases, new documents, new ideas for products \\
\hline
\end{tabular}

Table 2 User groups of knowledge creation environment.

\begin{tabular}{|c|c|c|}
\hline User group & Knowledge involved & Role \\
\hline $\begin{array}{l}\text { Engineering } \\
\text { Procurement and } \\
\text { Construction } \\
\text { personnel } \\
\end{array}$ & $\begin{array}{l}\text { Equipment configuration, plant } \\
\text { construction and purchasing } \\
\text { knowledge }\end{array}$ & \multirow{3}{*}{$\begin{array}{l}\text { Entering knowledge within the } \\
\text { responsibility area of the user } \\
\text { group. Verification of the } \\
\text { knowledge is mainly delegated } \\
\text { to the leading expert of the } \\
\text { technical area. }\end{array}$} \\
\hline Sales personnel & $\begin{array}{l}\text { Product structure and sales } \\
\text { knowledge }\end{array}$ & \\
\hline Product developers & $\begin{array}{l}\text { Product structure and product } \\
\text { constraint knowledge }\end{array}$ & \\
\hline $\begin{array}{l}\text { Knowledge creation } \\
\text { environment } \\
\text { developers } \\
\text { (knowledge } \\
\text { engineers) }\end{array}$ & \multirow[t]{2}{*}{$\begin{array}{l}\text { Product structure, product } \\
\text { constraint, equipment } \\
\text { configuration, plant } \\
\text { construction and purchasing } \\
\text { knowledge }\end{array}$} & $\begin{array}{l}\text { Browsing the entered } \\
\text { knowledge and reformulation of } \\
\text { the knowledge if necessary, } \\
\text { user support and development } \\
\text { of the knowledge creation } \\
\text { environment }\end{array}$ \\
\hline $\begin{array}{l}\text { Expert system } \\
\text { developers }\end{array}$ & & $\begin{array}{l}\text { Browsing the entered } \\
\text { knowledge for implementation } \\
\text { purposes and reporting of the } \\
\text { implemented knowledge }\end{array}$ \\
\hline
\end{tabular}


Leading experts and knowledge engineers are mining knowledge so that they can describe the logical knowledge structures of product, design and project delivery. Knowledge engineers can also define the structure of the data warehouse and component structure in the expert system. "Active

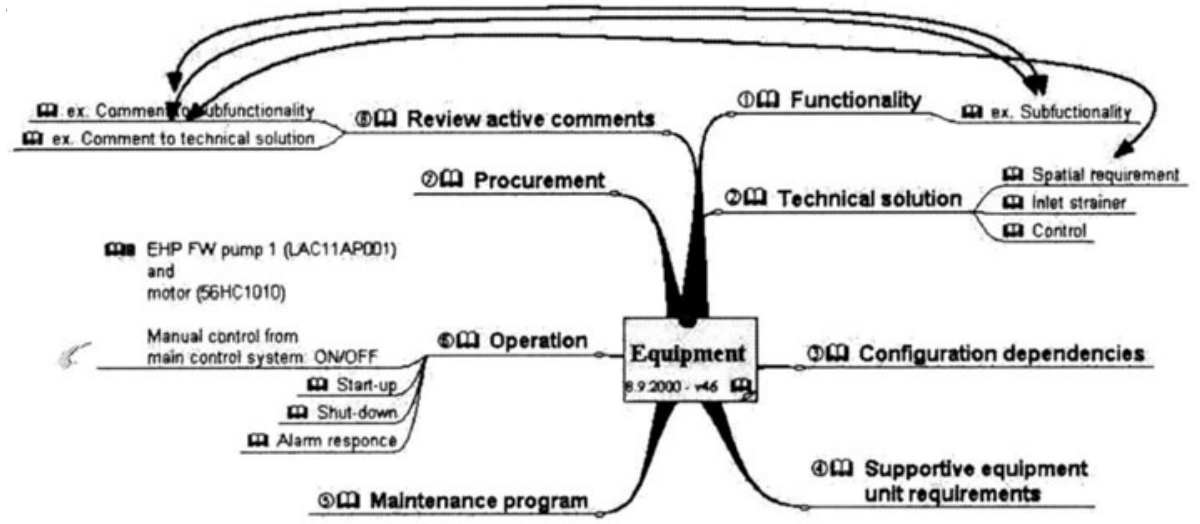

Figure 5 Informal mapping of knowledge by Mind Mapping

It is possible to work concurrently with different experts and at the same time to have joint evaluations in meetings. Furthermore, the mind mapping application may be used as a case-tool for WEB application development. This may then be used for browsing, proposing, entering, modifying, verifying and validating of knowledge.

\subsection{Structured Mapping}

In structured mapping, the collected and created rules and associated structures are stored in knowledge repository, which is a relational database. Work between informal and structured mapping is manually defined using UML. Figure 6 gives an example how formal mapping is supported. The knowledge is connected to a product model tree at the left-hand side of the dialog with the same semantics as that of the informal mapping (Figure 5).

\section{CONCLUSION}

This paper presented the underlying motivation and commitment of Fortum Engineering towards the development of its knowledge creation environment. The key point is the translation of scattered tacit knowledge to 
more meaningful and structured explicit knowledge for use in expert applications where possible.

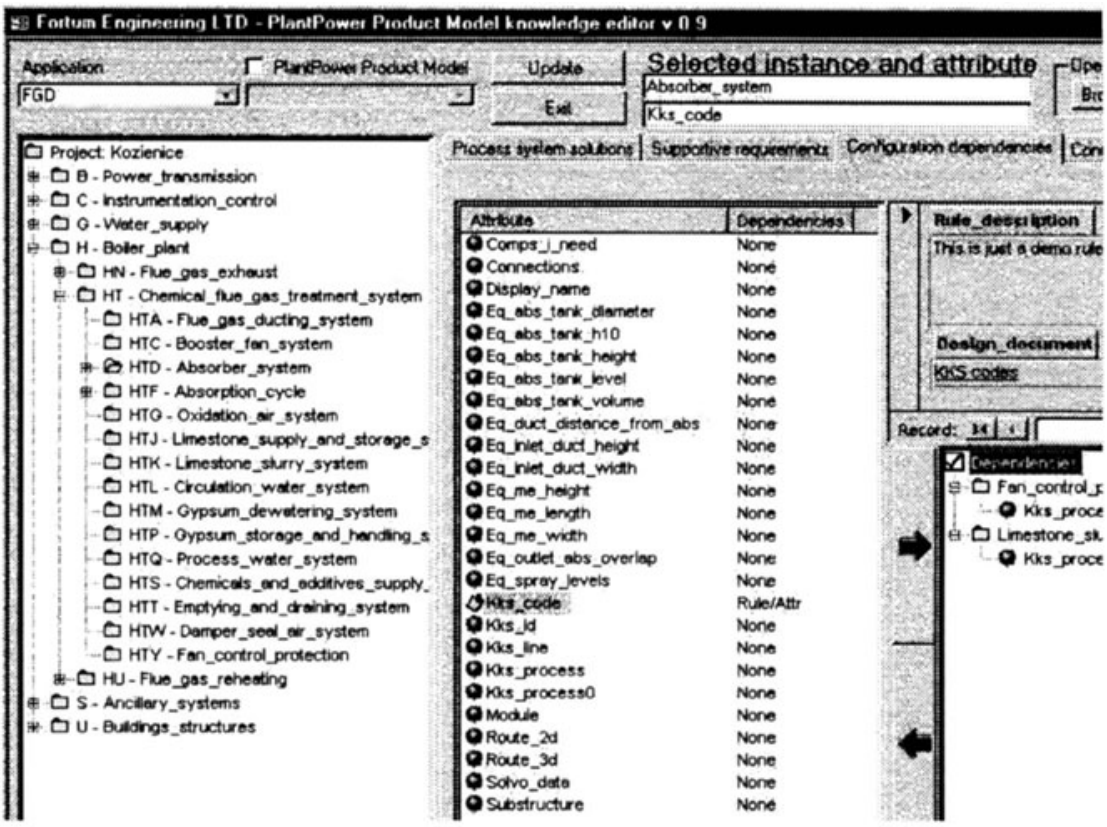

Figure 6 User interface to formal mapping of knowledge

This is an ongoing development work and only some initial lessons have been learned and insights into the future have been provided. More findings will be reported and published as they become available during the course of the development of the knowledge creation environment.

\section{REFERENCES}

[1] Kazi A.S., Puttonen J., Sulkusalmi M., Valikangas P., Hannus M. (2000 forthcoming) Knowledge Creation and Management: The Case of Fortum Engineering Ltd., Knowledge Management in the Sociotechnical World.

[2] Nonaka I., Takeuchi H. (1994). The Knowledge-Creating Company, ISBN 0-19509269-4

[3] Davenport T. H., Prusak L. (1992). Working Knowledge, ISBN 1-57851-301-4 (pbk)

[4] von Krogh G., Ichijo K., Nonaka I. (2000). Enabling Knowledge Creation, ISBN 0-19512616-5 